\title{
Low incidence of multidrug-resistant bacteria and nosocomial infection due to a preventive multimodal nosocomial infection control: a 10-year single centre prospective cohort study in neurocritical care
}

Vera Spatenkova ${ }^{1 *}$ D, Ondrej Bradac ${ }^{2}$, Daniela Fackova ${ }^{3}$, Zdenka Bohunova $^{3}$ and Petr Suchomel ${ }^{4}$

\begin{abstract}
Background: Nosocomial infection (NI) control is an important issue in neurocritical care due to secondary brain damage and the increased morbidity and mortality of primary acute neurocritical care patients. The primary aim of this study was to determine incidence of nosocomial infections and multidrug-resistant bacteria and seek predictors of nosocomial infections in a preventive multimodal nosocomial infection protocol in the neurointensive care unit (NICU). The secondary aim focused on their impact on stay, mortality and cost in the NICU.

Methods: A10-year, single-centre prospective observational cohort study was conducted on 3464 acute brain disease patients. There were 198 (5.7\%) patients with nosocomial infection (wound 2.1\%, respiratory 1.8\%, urinary 1. 0\%, bloodstream 0.7\% and other 0.1\%); 67 (1.9\%) with Extended spectrum beta-lactamase (ESBL); 52 (1.5\%) with Methicillin-resistant Staphylococcus aureus (MRSA), nobody with Vancomycin-resistant enterococcus (VRE). The protocol included hygienic, epidemiological status and antibiotic policy. Univariate and multivarite logistic regression analysis was used for identifying predictors of nosocomial infection.

Results: From $198 \mathrm{NI}$ patients, 153 had onset of NI during their NICU stay (4.4\%; wound 1.0\%, respiratory 1.7\%, urinary 0. 9\%, bloodstream 0.6\%, other 0.1\%); ESBL in 31 (0.9\%) patients, MRSA in $30(0.9 \%)$ patients. Antibiotics in prophylaxis was given to $63.0 \%$ patients (59.2\% for operations), in therapy to $9.7 \%$ patients. Predictors of $\mathrm{NI}$ in multivariate logistic regression analysis were airways (OR 2.69, 95\% Cl 1.81-3.99, $p<0.001)$, urine catheters (OR $2.77,95 \% \mathrm{Cl} 1.00-7.70$, $p=0.050$ ), NICU stay (OR 1.14,95\% Cl 1.12-1.16, $p<0.001$ ), transfusions (OR 1.79, 95\% Cl 1.07-2.97, $p=0.025$ ) antibiotic prophylaxis (OR 0.50, 95\% Cl 0.34-0.74, $p<0.001)$, wound complications (OR 2.30, 95\% Cl 1.33-3.97, $p=0.003)$. NI patients had longer stay $(p<0.001)$, higher mortality $(p<0.001)$ and higher TISS sums $(p<0.001)$ in the NICU.

Conclusions: The presented preventive multimodal nosocomial infection control management was efficient; it gave low rates of nosocomial infections (4.2\%) and multidrug-resistant bacteria (ESBL 0.9\%, MRSA 0.9\% and no VRE). Strong predictors for onset of nosocomial infection were accesses such as airways and urine catheters, NICU stay, antibiotic prophylaxis, wound complications and transfusion. This study confirmed nosocomial infection is associated with worse outcome, higher cost and longer NICU stay.
\end{abstract}

Keywords: Neurocritical care, Nosocomial infections, Multidrug-resistant bacteria, Outcome, Preventive protocol

\footnotetext{
*Correspondence: vera.spatenkova@nemlib.cz

${ }^{1}$ Neurocenter, Neurointensive Care Unit, Regional Hospital, Husova 357/10,

Regional Hospital, 46063 Liberec, Czech Republic

Full list of author information is available at the end of the article
} 


\section{Background}

Nosocomial infections (NI) are still an important issue in neurocritical care due to secondary brain damage and the increased morbidity and mortality of primary acute neurocritical care patients [1-5]. NI is associated with higher antibiotic consumption, thereby worsening the epidemiological situation in the intensive care unit by increasing the occurrence of multidrug-resistant bacteria [6]. For these reasons, they have a significant economic impact because they prolong stay [7-10] in the neurointensive care unit (NICU) and the higher frequency of diagnostic and therapeutic processing significantly raises healthcare costs

Nosocomial infections can be caused by many risk factors, not all of which have been fully investigated. However, keeping a hygienic and epidemiological regime of critical care [11-13] and the rational use of antibiotics makes a significant impact $[14,15]$.

The primary aim of this study was to determine incidence of nosocomial infections and multidrug-resistant bacteria and seek predictors of nosocomial infections in a preventive multimodal nosocomial infection protocol in our neurocritical care. The secondary aim focused on their impact on stay, mortality and cost in the NICU.

\section{Method}

\section{Study design and setting}

A monocentric 10-year observation prospective cohort study was conducted in the entire population of 3464 patients with acute brain disease, admitted to an eight-bed, adult neurological and neurosurgical intensive care unit in the Neurocenter of the 900-bed Regional Hospital with a catchment area of approximately half a million people. The study was performed in the NICU, which consists of four different rooms: one room with one bed, two rooms with two beds and one room with three beds. The study was approved by the Liberec hospital Ethics Committees for Multicentric Clinical Trials.

We prospectively examined the following determined demographic and clinical parameters in our local NICU: brain diagnosis, type of admission (primary, secondary to 24 hours and after 24 hours; acute or planned; rehospitalisation), admission and overall Therapeutic Intervention Scoring System (TISS), admission Glasgow Coma Scale (GCS), admission Acute Physiology and Chronic Health Evaluation (APACHE) II score, length of stay in the NICU, mortality in the NICU, Glasgow Outcome Scale (GOS) upon discharge from the NICU, C-reactive protein (CRP), operations (amount, day of hospital and NICU hospitalisation, acute or planned, reoperation, time and type of operation), American Society of Anesthesiologists (ASA) Score, drainage, airways, mechanical ventilation, catheters (artery, central venous, urine) and tubes, administration of corticoids, transfusions, ulcer prophylaxis and diabetes mellitus.

\section{Preventive multimodal nosocomial infection protocol}

In the preventive multimodal nosocomial infection protocol, we categorised hygienic and epidemiological status and antibiotic policy.

\section{Hygienic and epidemiological regime}

The basis of the hygienic and epidemiological regime in our preventive multimodal protocol consisted of cleanliness, disinfection, sterilisation, barrier patient care techniques, the separation of clean and contaminated procedures and the regular monthly exchange of disinfectants. We categorised principles for staff, patients and facilities.

\section{$1 /$ Staff and visitors}

The foremost part of this protocol was maintaining the hygiene and disinfection of all staff members' hands before and after care for each patient, enabled by the bottled disinfectant provided at each entrance and each bed. This rule was also required for visitors. Staff members were not allowed to wear jewellery or watches on their hands and had to keep their fingernails cut short. Internal staff had to wear new, clean, special NICU clothing every day, a protective coat when outside the NICU, and masks, surgical caps and gowns when caring for isolated patients or during invasive medical procedures. Aprons were worn while washing patients. External staff as well as visitors wore surgical gowns, but not overshoes, and only 2 family members were allowed in the patient's room at a time.

\section{2/Patients}

Care of the patient was performed on the principle of barrier care techniques. Tools for individual patients including disinfection, stethoscopes, thermometers and washing aids were available by each bed. Patients were washed twice a day with liquid soap. Disinfection soap was used only before entering the operating theatre. Oral hygiene included cleaning teeth with our special toothbrushes with chlorhexidine and subglottic secretion drainage, after washing, the patient's body was rubbed with a non-allergic cream. Patients' clothes and bedding were changed twice a day. Dirty laundry was put in special sacks rather than dropped freely on the floor.

Basic principles of care for drainage, catheters, infusion, suction from the airway, breathing circuit sets, tubes included: 1 /single-use products, $2 /$ closed systems, $3 /$ the minimum necessary duration, $4 /$ minimal and only necessary disconnection, using the port system, 5/the regular (peripheral venous catheters, all infusion sets, connecting tubes and ports) and irregular (central venous catheters, endotracheal tubes and tracheostomy) exchange of all these tubes and catheters was made according to the exchange protocol. Invasive procedures included the sterile insertion of systems and regularly exchanged, fully covering and 
Table 1 Demographic and clinical data of population of patients with acute brain disease, with or without nosocomial infection

\begin{tabular}{|c|c|c|c|c|c|}
\hline Parameter & Unit & Total population & $\mathrm{Nl}$ group & Control group & $p$ value \\
\hline Number total & pts & $3464(100 \%)$ & 198 (5.7\%) & 3266 (94.3\%) & \\
\hline January & pts & 327 (9.4\%) & $7(3.6 \%)$ & $310(9.5 \%)$ & \\
\hline February & pts & $249(7.2 \%)$ & 19 (9.6\%) & $230(7.0 \%)$ & \\
\hline March & pts & 267 (7.7\%) & 19 (9.6\%) & $248(7.6 \%)$ & \\
\hline April & pts & 305 (8.8\%) & $13(6.6 \%)$ & 292 (8.9\%) & \\
\hline May & pts & $269(7.8 \%)$ & $21(10.6 \%)$ & $248(7.6 \%)$ & \\
\hline June & pts & $290(8.4 \%)$ & 17 (8.6\%) & $273(8.4 \%)$ & 0.660 \\
\hline July & pts & 310 (8.9\%) & 19 (9.6\%) & 291 (8.9\%) & \\
\hline August & pts & 274 (7.98\%) & $12(6.1 \%)$ & $262(8.0 \%)$ & \\
\hline September & pts & 307 (8.9\%) & 14 (7.1\%) & $293(9.0 \%)$ & \\
\hline October & pts & $280(8.1 \%)$ & $13(6.6 \%)$ & 267 (8.2\%) & \\
\hline November & pts & $291(8.4 \%)$ & 17 (8.6\%) & $274(8.4 \%)$ & \\
\hline December & pts & $295(8.5 \%)$ & 17 (8.6\%) & $278(8.5 \%)$ & \\
\hline Age & pts & & $57.2 \pm 15.6$ & $56.3 \pm 15.6$ & 0.416 \\
\hline Male & pts & 2004 (57.9\%) & 117 (59.1\%) & 1887 (57.8\%) & 0.716 \\
\hline Weight & $\mathrm{kg}$ & & $78.7 \pm 17.1$ & $77.6 \pm 15.8$ & 0.423 \\
\hline $\mathrm{BMI}$ & & & $26.8 \pm 5.0$ & $26.8 \pm 4.9$ & 0.966 \\
\hline NICU stay & day & & $15.3 \pm 11.7$ & $4.8 \pm 5.4$ & $<0.001$ \\
\hline \multicolumn{6}{|l|}{ Admission } \\
\hline Primary & pts & 746 (21.5\%) & 47 (23.7\%) & $699(21.4 \%)$ & \\
\hline Secondary to $24 \mathrm{~h}$ & pts & 739 (21.3\%) & $51(25.8 \%)$ & $688(21.1 \%)$ & 0.134 \\
\hline Secondary after $24 \mathrm{~h}$ & pts & 1979 (57.1\%) & $100(50.5 \%)$ & 1879 (57.5\%) & \\
\hline Acute admission & pts & $1020(29.4 \%)$ & 70 (35.4\%) & $950(29.1 \%)$ & $<0.001$ \\
\hline Rehospitalisation & pts & $40(1.22 \%)$ & $4(2.0 \%)$ & $44(1.3 \%)$ & 0.331 \\
\hline \multicolumn{6}{|l|}{ Diagnoses } \\
\hline Stroke & pts & 1498 (43.2\%) & $110(55.6 \%)$ & 1388 (42.5\%) & \\
\hline Trauma & pts & $472(13.6 \%)$ & $27(13.6 \%)$ & $445(13.6 \%)$ & \\
\hline Tumour & pts & 1078 (31.1\%) & $33(16.7 \%)$ & 1045 (32.0\%) & $<0.001$ \\
\hline Epilepsy & pts & $133(3.8 \%)$ & $3(1.5 \%)$ & $130(4.0 \%)$ & \\
\hline Hydrocephalus & pts & 119 (3.4\%) & $13(6.6 \%)$ & $106(3.2 \%)$ & \\
\hline Infection & pts & $88(2.5 \%)$ & $11(5.6 \%)$ & 77 (2.4\%) & \\
\hline Others & pts & $75(2.2 \%)$ & $1(0.5 \%)$ & $74(2.3 \%)$ & \\
\hline Stroke & pts & & & & $<0.001$ \\
\hline Ischemic & pts & $580(16.7 \%)$ & $21(10.6 \%)$ & $559(17.1 \%)$ & \\
\hline $\mathrm{ICH}$ & pts & $471(13.6 \%)$ & 49 (24.7\%) & $422(12.9 \%)$ & \\
\hline $\mathrm{SAH}$ & pts & 447 (12.9\%) & $40(20.2 \%)$ & $407(12.5 \%)$ & \\
\hline TISS on admission & & & $54.7 \pm 1.9$ & $56.0 \pm 1.7$ & $<0.001$ \\
\hline TISS total & & & $270632.8 \pm 231533.1$ & $60415.1 \pm 92140 . .3$ & $<0.001$ \\
\hline GCS on admission & & & $11.5 \pm 3.5$ & $13.1 \pm 3.0$ & $<0.001$ \\
\hline APACHE II on admission & & & $15.1 \pm 5.5$ & $11.8 \pm 5.8$ & $<0.001$ \\
\hline GOS on NICU discharge & & & $3.1 \pm 1.1$ & $3.9 \pm 1.1$ & $<0.001$ \\
\hline Mortality in NICU & pts & $152(4.4 \%)$ & $21(10.6 \%)$ & $131(4.0 \%)$ & $<0.001$ \\
\hline Mortality in NICU & day & & $16.2 \pm 10.4$ & $7.5 \pm 5.7$ & $<0.001$ \\
\hline
\end{tabular}


Table 1 Demographic and clinical data of population of patients with acute brain disease, with or without nosocomial infection (Continued)

\begin{tabular}{|c|c|c|c|c|c|}
\hline Parameter & Unit & Total population & $\mathrm{Nl}$ group & Control group & $p$ value \\
\hline CRP on admission & & & $31.7 \pm 45.6$ & $17.5 \pm 39.1$ & $<0.001$ \\
\hline CRP postoperative & & & $30.0 \pm 44.4$ & $14.0 \pm 33.0$ & $<0.001$ \\
\hline CRP 1 day after operation & & & $59.8 \pm 56.9$ & $31.6 \pm 39.6$ & $<0.001$ \\
\hline CRP highest in NICU stay & & & $228.0 \pm 122.5$ & $66.1 \pm 80.3$ & $<0.001$ \\
\hline
\end{tabular}

$B M I$ body mass index, NICU neurointensive care unit, ICH intracerebral haemorrhage, SAH subarachnoid haemorrhage, TISS Therapeutic Intervention Scoring System, GCS Glasgow Coma Scale, APACHE Acute Physiology and Chronic Health Evaluation, GOS Glasgow Outcome Scale, CRP C-reactive protein

constantly dry sterile wound covers. Furthermore, the protocol included the hourly monitoring of residual gastric volume.

The protocol included the regular microbiological screening of nose, throat, trachea, skin, urine and rectum from admission and then every three days, as well as every catheter except the peripheral venous for the timely detection of multidrug-resistant bacteria extended spectrum beta-lactamases (ESBL) or methicillin-resistant Staphylococcus aureus (MRSA) or Vancomycin-resistant enterococcus (VRE).

Patients with an infection or with multidrug-resistant bacteria ESBL and MRSA were completely isolated.

\section{3/Facilities}

Daily cleaning with disinfection of surfaces including the bed, monitors, and other equipment around the bed, door handles and floors was conducted three times a day. Walls were cleaned once a day for the isolated patients, otherwise once a week. Each room had its own bucket for surfaces and walls. The floors were mopped using a system of two buckets and a cloth, with each room having its own. All cupboards containing materials and medical equipment were cleaned with disinfectant once a week. Waste was sorted and disposed of using specially marked plastic containers and sacks. After the patient was discharged, the bed was completely disinfected. The room was painted with a washable coating once a year.

\section{Antibiotic policy}

The protocol included the monitoring of antibiotics in a local computer database. Antibiotic policy was implemented in close cooperation with the antibiotic centre and intended to keep the rational antibiotic policy aim of eliminating the overuse of antibiotics, especially those not used during bacterial pathogeny colonisation. The indications for using prophylactic antibiotics were surgical procedures (operation, external ventricular and lumbar drainage, intracranial sensors), liquorrhoea and aspiration. The protocol required maintaining dose and timing before the operation, perioperative administration for lengthy operations, and the non-prolongation of antibiotic administration after the operation or drainage or implantation of sensors. Empiric antibiotic therapy was to start after samples were taken for microbiological examination to enable their administration according to culture and sensitivity.

\section{Nosocomial infection}

Infections were identified according to clinical symptoms such as fever, bacterial pathogens from secretions, liquor, urine, wounds, catheters, haemoculture with a defined microbiology colony count, imaging methods, biochemical and haematological laboratory tests. Nosocomial infections were defined as infections starting after two calendar days in the hospital. We identified nosocomial infections in 198 patients (5.7\%). There were more wound infections (2.1\%), than respiratory $(1.8 \%)$, urinary $(1.0 \%)$, bloodstream $(0.7 \%)$ and others $(0.1 \%)$.

\section{Statistical analysis}

Parametric $t$-tests or non-parametric Mann-Whitney $U$ tests were used for comparison of continuous variables. Comparison of categorical parameters was carried out using Chi-square or Fisher tests as appropriate. Univariate logistic regression was used for identifying prognostic factors of NI. Factors from univarite analysis with level of significance defined as $p<0.1$ were used for multivarite regression analysis, factors with $p$ value $<0.1$ were left in the model. $P$-values of less than 0.05 were considered significant. STATISTICA 13.2 (TIBCO Software Inc., Palo Alto, CA, USA) software was used for statistical analyses. The control group was defined as patients without nosocomial infections.

\section{Results}

We did not find any demographic differences such as age, gender, weight or body mass index between the NI group and the control group, as can be seen in Table 1. However, there was a difference in diagnosis, more patients with stroke and hydrocephalus had more NI than those with other diagnoses. According to the scoring system, patients with nosocomial infection upon admission had significantly lower GCS scale and higher APACHE II. Prognostic parameters were also significantly higher in the NI patients group. They stayed in the NICU longer, had higher mortality and worse Glasgow Coma Scale upon discharge. 
Table 2 Characteristics of brain operations

\begin{tabular}{|c|c|c|c|c|c|}
\hline Operation & Unit & Total population $N=2231$ & $\mathrm{Nl}$ group $N=151$ & Control group $N=2080$ & $p$ value \\
\hline Operation & pts & $2231(64.4 \%)$ & $151(76.3 \%)$ & $2080(63.7 \%)$ & $<0.001$ \\
\hline More than 1 operation & pts & $214(9.6 \%)$ & $42(27.8 \%)$ & $172(8.3 \%)$ & $<0.001$ \\
\hline ASA score & & & $3.8 \pm 1.0$ & $3.1 \pm 1.1$ & $<0.001$ \\
\hline Day of hospitalisation & day & & $5.5 \pm 9.8$ & $7.1 \pm 17.1$ & 0.430 \\
\hline Day of NICU & & & $1.6 \pm 1.3$ & $1.3 \pm 1.1$ & 0.535 \\
\hline Acute operation & pts & $905(40.6 \%)$ & $106(70.2 \%)$ & 799(38.4\%) & $<0.001$ \\
\hline Reoperation & pts & $479(21.5 \%)$ & $58(38.4 \%)$ & $421(20.2 \%)$ & $<0.001$ \\
\hline Time of operation & minutes & & $151.9 \pm 108.4$ & $137.7 \pm 89.4$ & 0.080 \\
\hline Craniotomy & pts & $1361(61.0 \%)$ & $82(54.3 \%)$ & $1279(61.5 \%)$ & 0.080 \\
\hline Craniectomy & pts & $363(16.3 \%)$ & $50(33.1 \%)$ & $313(15.0 \%)$ & $<0.001$ \\
\hline Trepanation & pts & $227(10.2 \%)$ & $23(15.2 \%)$ & $204(9.8 \%)$ & 0.033 \\
\hline Hypophysis & pts & $85(3.8 \%)$ & $0(0.0 \%)$ & $85(4.1 \%)$ & 0.011 \\
\hline Shunt & pts & $108(4.8 \%)$ & $12(7.9 \%)$ & $96(4.6 \%)$ & 0.066 \\
\hline Others & pts & $99(4.4 \%)$ & $9(6.0 \%)$ & $90(4.3 \%)$ & 0.347 \\
\hline Drainage & pts & 1678(75.2\%) & $131(86.8 \%)$ & $1547(74.4 \%)$ & $<0.001$ \\
\hline Redon & pts & $858(38.5 \%)$ & 49(32.5\%) & $809(38.9 \%)$ & 0.001 \\
\hline Time overall & day & & $2.0 \pm 0.9$ & $1.8 \pm 1.3$ & 0.395 \\
\hline Gravity drainage & pts & $807(36.2 \%)$ & $75(49.7 \%)$ & $732(35.2 \%)$ & 0.029 \\
\hline Time overall & day & & $3.5 \pm 2.1$ & $2.7 \pm 2.2$ & 0.004 \\
\hline Lumbar & pts & $218(9.8 \%)$ & $36(23.8 \%)$ & $182(8.8 \%)$ & $<0.001$ \\
\hline Day overall & day & & $7.7 \pm 5.5$ & $5.1 \pm 3.2$ & $<0.001$ \\
\hline Ventricular & pts & $138(6.2 \%)$ & $21(13.9 \%)$ & $117(5.6 \%)$ & $<0.001$ \\
\hline Day overall & day & & $13.4 \pm 9.9$ & $5.9 \pm 4.3$ & $<0.001$ \\
\hline
\end{tabular}

ASA American Society of Anesthesiologists, NICU neurointensive care unit

Table 3 Characteristics of respiratory procedures

\begin{tabular}{|c|c|c|c|c|c|}
\hline Parameter & Unit & Total population $N=3646$ & $\mathrm{Nl}$ group $N=198$ & $\begin{array}{l}\text { Control group } \\
N=3266\end{array}$ & $p$ value \\
\hline Airways & pts & $710(20.5 \%)$ & $112(56.6 \%)$ & $598(18.3 \%)$ & \multirow[t]{2}{*}{$<0.001$} \\
\hline ETT & pts & $327(46.1 \%)$ & $15(13.4 \%)$ & $312(52.2 \%)$ & \\
\hline TSK & pts & $161(22.7 \%)$ & $29(25.9 \%)$ & $132(22.1 \%)$ & \multirow[t]{2}{*}{$<0.001$} \\
\hline ETT/TST & pts & $222(31.3 \%)$ & $68(60.7 \%)$ & 154(25.8\%) & \\
\hline ETK time NICU & day & & $4.2 \pm 2.1$ & $2.9 \pm 2.2$ & $<0.001$ \\
\hline ETK time & day & & $4.4 \pm 2.1$ & $2.9 \pm 2.3$ & $<0.001$ \\
\hline TSK time NICU & day & & $14.2 \pm 10.2$ & $8.4 \pm 7.8$ & $<0.001$ \\
\hline TSK time & day & & $21.8 \pm 34.6$ & $21.6 \pm 62.2$ & 0.980 \\
\hline TSK type Classic & pts & $43(11.2 \%)$ & $9(9.3 \%)$ & $34(11.9 \%)$ & 0.456 \\
\hline TSK NICU made & pts & $250(65.3 \%)$ & 75(77.3\%) & $175(61.2 \%)$ & 0.006 \\
\hline Mechanical ventilation & pts & $543(15.7 \%)$ & $87(43.9 \%)$ & $456(14.0 \%)$ & $<0.001$ \\
\hline Invasive & pts & 539(99.3\%) & $87(100.0 \%)$ & 452(99.1\%) & $<0.001$ \\
\hline Time & day & & $14.1 \pm 9.9$ & $5.6 \pm 5.9$ & $<0.001$ \\
\hline \multicolumn{6}{|l|}{ Indication } \\
\hline Neuro & pts & 414(76.2\%) & $54(62.1 \%)$ & $360(78.9 \%)$ & \multirow[t]{2}{*}{0.161} \\
\hline Respiratory & pts & $32(5.9 \%)$ & 7(8.0\%) & $25(5.5 \%)$ & \\
\hline
\end{tabular}


They were also more expensive economically, and had significantly higher total TISS.

Characteristics of brain operations can be seen in Table 2. Patients who had undergone operations and drainage had significantly higher nosocomial infection. These patients had more endotracheal tubes and tracheostomies, mechanical ventilations (Table 3), artery and central venous catheters (Table 4), urine and gastrointestinal tubes (Table 5).

We confirmed transfusions $(p<0.001)$, ulcer prophylaxis $(p<0.001)$ and corticoids $(p=0.002)$ as further parameters influencing nosocomial infection, but we did not see more

Table 4 Characteristics of vascular catheters

\begin{tabular}{|c|c|c|c|c|c|}
\hline Parameter & Unit & Total population $N=3464$ & $\mathrm{Nl}$ group $N=198$ & Control group $N=3266$ & $p$ value \\
\hline Artery catheter & pts & $907(26.2 \%)$ & $90(45.5 \%)$ & $817(25.0 \%)$ & $<0.001$ \\
\hline Time & day & & $9.5 \pm 6.6$ & $7.5 \pm 3.7$ & 0.018 \\
\hline Number of artery catheters & & $923(100.0 \%)$ & $91(100.0 \%)$ & $832(100.0 \%)$ & \\
\hline Radialis & pts & $873(94.6 \%)$ & $89(97.8 \%)$ & $784(94.2 \%)$ & 0.165 \\
\hline Brachialis & pts & $14(1.5 \%)$ & $0(0.0 \%)$ & $14(1.7 \%)$ & 0.211 \\
\hline Femoralis & pts & $36(3.9 \%)$ & $2(2.2 \%)$ & $34(4.1 \%)$ & 0.371 \\
\hline Left & pts & $598(64.8 \%)$ & $64(70.3 \%)$ & $534(64.2 \%)$ & 0.275 \\
\hline Time in NICU & day & & $8.27 \pm 5.45$ & $4.10 \pm 3.36$ & 0.094 \\
\hline Time all & day & & $8.41 \pm 5.40$ & $4.41 \pm 3.43$ & 0.377 \\
\hline Made in NICU & pts & $216(23.4 \%)$ & $47(51.6 \%)$ & $169(20.3 \%)$ & $<0.001$ \\
\hline Made in operation theatre & pts & $607(65.8 \%)$ & $46(50.5 \%)$ & $561(67.4 \%)$ & 0.001 \\
\hline Cultivation of catheter & pts & $691(74.9 \%)$ & 74(81.3\%) & $617(74.2 \%)$ & 0.157 \\
\hline Positive & pts & $113(16.4 \%)$ & 18(24.3\%) & 95(15.4\%) & 0.050 \\
\hline STSP & pts & $100(88.5 \%)$ & $13(72.2 \%)$ & $87(91.6 \%)$ & 0.018 \\
\hline Haemoculture cultivation & pts & $164(17.8 \%)$ & $31(34.1 \%)$ & 133(16.0\%) & $<0.001$ \\
\hline Positive & pts & $34(20.7 \%)$ & $9(29.0 \%)$ & $25(18.8 \%)$ & 0.206 \\
\hline STSP & pts & $18(52.9 \%)$ & $3(33.3 \%)$ & $15(60.0 \%)$ & 0.169 \\
\hline Central venous catheter & pts & $372(10.7 \%)$ & $64(32.3 \%)$ & $308(9.4 \%)$ & $<0.001$ \\
\hline Time overall & day & & $9.9 \pm 7.4$ & $7.5 \pm 3.7$ & 0.077 \\
\hline Number of venous catheter & & $378(100 \%)$ & $66(100 \%)$ & $312(100 \%)$ & \\
\hline Subclavia & pts & 336(88.9\%) & $60(90.9 \%)$ & $276(88.5 \%)$ & 0.308 \\
\hline Jugularis & pts & 19(5.0\%) & $1(1.5 \%)$ & $18(5.8 \%)$ & 0.157 \\
\hline Femoralis & pts & $16(4.2 \%)$ & $4(6.1 \%)$ & $12(3.8 \%)$ & 0.398 \\
\hline Axilaris & pts & $7(1.9 \%)$ & $1(1.5 \%)$ & $6(1.9 \%)$ & 0.836 \\
\hline Right & pts & $323(85.4 \%)$ & $59(89.4 \%)$ & 264(84.6\%) & 0.164 \\
\hline Type one-line & pts & $75(19.8 \%)$ & 10(15.2\%) & $65(20.8 \%)$ & \\
\hline Type two-line & pts & 192(50.8\%) & $39(59.1 \%)$ & 153(49.0\%) & 0.214 \\
\hline Type three-line & pts & $64(16.9 \%)$ & $8(12.1 \%)$ & $56(17.9 \%)$ & \\
\hline Time in NICU & day & & $8.20 \pm 7.31$ & $4.70 \pm 4.92$ & $<0.001$ \\
\hline Time all & day & & $11.19 \pm 8.70$ & $7.24 \pm 5.50$ & $<0.001$ \\
\hline Made in NICU & pts & $162(42.9 \%)$ & $41(62.1 \%)$ & $121(38.8 \%)$ & $<0.001$ \\
\hline Made in operation theatre & pts & $14(3.7 \%)$ & $1(1.5 \%)$ & $13(4.2 \%)$ & 0.309 \\
\hline Cultivation of catheter & pts & $261(69.0 \%)$ & $45(68.2 \%)$ & $216(69.2 \%)$ & 0.977 \\
\hline Positive & pts & $52(19.9 \%)$ & 16(35.6\%) & $36(16.7 \%)$ & 0.004 \\
\hline STSP & pts & $40(76.9 \%)$ & $10(62.5 \%)$ & $30(83.3 \%)$ & 0.010 \\
\hline Haemoculture cultivation & pts & $72(19.0 \%)$ & $16(24.2 \%)$ & $56(17.9 \%)$ & 0.090 \\
\hline Positive & pts & $15(20.8 \%)$ & $2(12.5 \%)$ & $13(23.2 \%)$ & 0.352 \\
\hline STSP & pts & 13(86.7\%) & $2(100.0 \%)$ & $11(84.6 \%)$ & 0.551 \\
\hline
\end{tabular}


Table 5 Characteristics of urine and gastrointestinal procedures

\begin{tabular}{|c|c|c|c|c|c|}
\hline Parameter & Unit & Total population $N=3464$ & $\mathrm{Nl}$ group $N=198$ & Control group $N=3266$ & $p$ value \\
\hline Urine catheter & pts & $3166(91.4 \%)$ & 189(95.5\%) & $2927(89.6 \%)$ & 0.008 \\
\hline Epicystostomy & pts & $6(0.2 \%)$ & $1(0.5 \%)$ & $5(0.2 \%)$ & 0.247 \\
\hline Time & day & & $15.5 \pm 11.6$ & $4.7 \pm 5.5$ & $<0.001$ \\
\hline Time overall & day & & $22.6 \pm 13.1$ & $12.8 \pm 9.7$ & $<0.001$ \\
\hline Gastrointestinal tube & pts & $904(26.1 \%)$ & $128(64.6 \%)$ & $776(23.8 \%)$ & $<0.001$ \\
\hline Nasogastric tube & pts & $882(25.5 \%)$ & $125(63.1 \%)$ & $757(23.2 \%)$ & $<0.001$ \\
\hline Time & day & & $15.4 \pm 11.2$ & $6.2 \pm 6.9$ & $<0.001$ \\
\hline Time overall & day & & $19.6 \pm 12.6$ & $10.7 \pm 9.4$ & $<0.001$ \\
\hline
\end{tabular}

nosocomial infection in patients with diabetes mellitus $(p=0.203)$, (Table 6).

ESBL occurred in $1.9 \%$ and MRSA in $1.5 \%$ of the total population, without differences between NI group patients and the control group (Table 7). We did not have any case of vancomycin-resistant enterococcus.

Antibiotics policy is shown in Table 8. Antibiotic prophylaxis was given to $63 \%$ of the total population, mostly (59.2\%) in association with operations. In $33.4 \%$ of the patients it was only administered in the operating theatre. Prolonged administration in the NICU was associated with more NIs $(p=0.017)$. Antibiotic therapy was given to $9.7 \%$ of the total population.

We compared patients with NI onset in the NICU (77.3\%) with NI present on admission (22.7\%), (Table 9). We identified 153 (4.4\%; wound 1.0\%, respiratory 1.7\%, urinary $0.9 \%$, bloodstream $0.6 \%$ and other $0.1 \%$ ) patients with NI onset in the NICU. Patients with NI onset in the NICU stayed in the NICU significantly longer, and were more expensive, but these patients did not have higher mortality. Multivariate logistic regression analysis seeking significant predictors for onset of NI in the NICU can be seen in Table 10. Our results showed that strong predictors on onset of NI in our neurocritical care were accesses such as airways and urine catheters, NICU stay, antibiotic prophylaxis, wound complications and transfusion. This analysis did not find the multidrug-resistant bacteria as ESBL and MRSA to be a predictor of NI.

\section{Discussion}

Maintaining nosocomial infection control management is one marker of quality in neurocritical care. Its target is to improve clinical outcomes and decrease costs in the neurocritical care unit. Preventions of nosocomial infections are an important issue in all medical or surgical critical care units, but in neurocritical care they have

Table 6 Further monitored parameters influencing onset of nosocomial infection

\begin{tabular}{|c|c|c|c|c|c|}
\hline Parameter & Unit & Total population $N=3464$ & NI group $N=198$ & Control group $N=3266$ & $p$ value \\
\hline Corticoids & pts & $1172(33.8 \%)$ & $47(23.7 \%)$ & $1125(34.4 \%)$ & 0.002 \\
\hline Dexamethasone & pts & $944(27.3 \%)$ & $31(15.7 \%)$ & $913(28.0)$ & $<0.001$ \\
\hline Methylprednisolone & pts & $35(1.0 \%)$ & $5(2.5 \%)$ & $30(0.9 \%)$ & 0.028 \\
\hline Hydrocortisone & pts & $241(7.0 \%)$ & $12(6.1 \%)$ & $229(7.0 \%)$ & 0.610 \\
\hline Time & day & & $6.37 \pm 8.78$ & $3.58 \pm 2.56$ & $<0.001$ \\
\hline Transfusions & pts & $176(5.1 \%)$ & $41(20.7 \%)$ & $135(4.1 \%)$ & $<0.001$ \\
\hline Number & & & $2.46 \pm 8.78$ & $2.57 \pm 2.56$ & 0.695 \\
\hline Blood loss & $\mathrm{ml}$ & & $523.77 \pm 668.07$ & $380.74 \pm 478.76$ & 0.019 \\
\hline Haemoglobin & & & $93.35 \pm 21.03$ & $115.34 \pm 21.62$ & $<0.001$ \\
\hline Ulcer prophylaxis & pts & 1838(53.1\%) & $134(67.7 \%)$ & $1704(52.2 \%)$ & $<0.001$ \\
\hline One medicine & pts & $1669(48.2 \%)$ & $119(60.1 \%)$ & $1550(47.5 \%)$ & 0.406 \\
\hline Sucralfate & pts & $758(21.9 \%)$ & $26(13.1 \%)$ & $732(22.4 \%)$ & 0.002 \\
\hline $\mathrm{H} 2$ antagonist & pts & 196(5.7\%) & $27(13.6 \%)$ & $169(5.2 \%)$ & $<0.001$ \\
\hline Omeprazole & pts & 1062(30.7\%) & $97(49.0 \%)$ & $965(29.5 \%)$ & $<0.001$ \\
\hline Diabetes Mellitus & pts & $491(14.2 \%)$ & $22(11.1 \%)$ & $469(14.4 \%)$ & 0.203 \\
\hline Op. wound complication & pts & $133(3.8 \%)$ & $35(17.7 \%)$ & $98(3.0 \%)$ & $<0.001$ \\
\hline Liquorrhoea & pts & $81(2.3 \%)$ & $23(11.6 \%)$ & $58(1.8 \%)$ & $<0.001$ \\
\hline
\end{tabular}


Table 7 Multidrug-resistant bacteria ESBL and MRSA in NICU

\begin{tabular}{llllll}
\hline Parameter & Unit & Total population N=3464 & Nl group N=198 & Control group N=3266 & $p$ value \\
\hline Multidrug-resistant & pts & $116(3.3 \%)$ & $12(6.1 \%)$ & $104(3.2 \%)$ & $61(1.9 \%)$ \\
ESBL & pts & $67(1.9 \%)$ & $6(3.0 \%)$ & $32(1.0 \%)$ & 0.029 \\
On admission & pts & $36(1.0 \%)$ & $4(2.0 \%)$ & $10(0.3 \%)$ & 0.566 \\
$\quad$ Nose & pts & $11(0.3 \%)$ & $1(0.5 \%)$ & $17(0.5 \%)$ & 0.986 \\
Throat & pts & $21(0.6 \%)$ & $4(2.0 \%)$ & $14(0.4 \%)$ & 0.051 \\
Trachea & pts & $15(0.4 \%)$ & $1(0.5 \%)$ & $19(0.6 \%)$ & 0.725 \\
Urine & pts & $19(0.5 \%)$ & $0(0.0 \%)$ & $28(0.9 \%)$ & 0.106 \\
Rectum & pts & $31(0.9 \%)$ & $3(1.5 \%)$ & $1(0.0 \%)$ & 0.848 \\
Brain & pts & $2(0.1 \%)$ & $1(0.5 \%)$ & $4(0.1 \%)$ & 0.039 \\
Others & pts & $5(0.1 \%)$ & $1(0.5 \%)$ & $45(1.4 \%)$ & 0.369 \\
MRSA & pts & $52(1.5 \%)$ & $7(3.5 \%)$ & $22(0.7 \%)$ & 0.320 \\
On admission & pts & $22(0.6 \%)$ & $0(0.0 \%)$ & $23(0.7 \%)$ & 0.015 \\
Nose & pts & $27(0.8 \%)$ & $4(2.0 \%)$ & $10(0.3 \%)$ & 0.766 \\
Throat & pts & $11(0.3 \%)$ & $1(0.5 \%)$ & $12(0.4 \%)$ & 0.632 \\
Trachea & pts & $14(0.4 \%)$ & $2(1.0 \%)$ & $1(0.1 \%)$ & 0.916 \\
Brain & pts & $5(0.1 \%)$ & $0(0.0 \%)$ & $0.5 \%)$ & 0.652 \\
Haemoculture & pts & $1(0.0 \%)$ & $0(0.0 \%)$ & $5(0.2 \%)$ & 0.690 \\
Others & pts & $5(0.1 \%)$ & 0.354
\end{tabular}

NICU neurointensive care unit, ESBL Extended spectrum beta-lactamase, MRSA Methicillin-resistant Staphylococcus aureus

an additional risk as a cause of secondary brain damage, which affects the morbidity and mortality of primary brain diseases [1-5]. As the aim of neurocritical care is to avoid all insults causing secondary brain damage, preventive management of nosocomial infections is a challenge for neurointensivists. Incidence of nosocomial infections can be reduced by keeping a hygienic and epidemiological regime and rational antibiotic policy. Nosocomial infection management demands constant maintenance and stable teamwork while maintaining standard procedures. We present our preventive multimodal nosocomial infection protocol, which we implemented in our NICU. The first phase involves imposing hygienic principles and the antibiotics policy. The second phase, actually keeping to this protocol, is a much more difficult task in our experience, as a vital component for its success is the participation of the whole team, from doctors and nurses to cleaners working in the neurocritical care unit and even visitors. The use of standard procedures and meticulous checks are an important part of the regime.

Here we present the impact of our preventive nosocomial infection management on the incidence of nosocomial infections in all the patients admitted to our NICU with acute brain disease. The results show that our preventive protocol was not sufficient to completely eliminate all nosocomial infections, but it did lead to a relatively low nosocomial infection incidence of $4.4 \%$. We did not observe differences between various seasons of the year, either among primary or secondary admissions, but we did among acute admissions, acute operations and reoperations. Infections were more frequently associated with strokes than other brain diagnoses. There were significantly more infections in airways, mechanical ventilations and catheters, but only airways and urine catheters were strong predictors in multivariate logistic regression analysis. These are still risk factors which remained despite the maintenance of the preventive strategy. Further predictors were confirmed to be the well-known factors of NICU stay, wound complications, antibiotic prophylaxis and transfusion.

The increasing colonisation of multidrug-resistant bacteria ESBL and MRSA is a big problem among critically ill patients and this situation is getting worse. At present, many patients already have these bacteria on admission and this colonization constitutes a risk of nosocomial infections [16-18]. We deal with this by completely isolating these patients using barrier care techniques in order to prevent the transmission of these multidrug-resistant ESBL and MRSA to other, uncolonised patients. This was reflected in our results, which showed that we had newly occurred ESBL in only in 31 (0.9\%) patients and MRSA in $30(0.9 \%)$ patients. In this study we did not find that multidrug-resistant bacteria were a predictor of nosocomial infections.

Antibiotics policy, predominantly the overuse of antibiotics, is another big issue in preventive multimodal nosocomial infection protocol. From our results, we see 
Table 8 Administration of antibiotics in NICU

\begin{tabular}{|c|c|c|c|c|c|}
\hline Parameter & Unit & Total population N=3464 & $\mathrm{Nl}$ group $N=198$ & Control group $N=3266$ & $p$ value \\
\hline Antibiotic prophylaxis & pts & $2183(63.0 \%)$ & $127(64.1 \%)$ & $2056(63.0 \%)$ & 0.736 \\
\hline One prophylaxis & pts & $1931(55.7 \%)$ & $91(46.0 \%)$ & $1840(56.3 \%)$ & $<0.001$ \\
\hline Operation & pts & 2049(59.2\%) & $116(58.6 \%)$ & $1933(59.2 \%)$ & 0.222 \\
\hline Only operation theatre & pts & $1157(33.4 \%)$ & $61(30.8 \%)$ & 1096(33.6\%) & \\
\hline Operation 1 dose & pts & $924(26.7 \%)$ & $42(21.2 \%)$ & $882(27.0 \%)$ & \\
\hline Operation 2 doses & pts & $191(5.5 \%)$ & $14(7.1 \%)$ & $177(5.4 \%)$ & 0.006 \\
\hline Operation 3 doses & pts & $40(1.2 \%)$ & $4(2.0 \%)$ & $36(1.1 \%)$ & \\
\hline Operation 4 doses & pts & $2(0.1 \%)$ & $1(0.5 \%)$ & $1(0.0 \%)$ & \\
\hline $\mathrm{NICU}$ & day & & $4.96 \pm 5.69$ & $3.31 \pm 2.88$ & 0.017 \\
\hline \multicolumn{6}{|l|}{ Others } \\
\hline Aspiration & pts & $51(1.5 \%)$ & $5(2.5 \%)$ & $46(1.4 \%)$ & 0.218 \\
\hline Suspected infection & pts & $49(1.0 \%)$ & $2(1.0 \%)$ & $47(1.4 \%)$ & 0.600 \\
\hline Trauma & pts & $30(1.4 \%)$ & $2(1.0 \%)$ & $28(0.9 \%)$ & 0.844 \\
\hline Liquorrhoea & pts & $46(0.9 \%)$ & $6(3.0 \%)$ & $40(1.2 \%)$ & 0.034 \\
\hline Drainage & pts & $35(1.3 \%)$ & $6(3.0 \%)$ & $29(0.9 \%)$ & 0.004 \\
\hline Others & pts & $31(1.0 \%)$ & $4(2.0 \%)$ & $27(0.8 \%)$ & 0.090 \\
\hline $\mathrm{NICU}$ & Day & & $7.75 \pm 4.61$ & $4.54 \pm 3.33$ & $<0.001$ \\
\hline \multicolumn{6}{|l|}{ Type of antibiotic } \\
\hline Cefazolin & pts & $1733(50.0 \%)$ & $106(53.5 \%)$ & $1627(49.8 \%)$ & 0.242 \\
\hline Amoxicillin clavulanate & pts & $362(10.5 \%)$ & $30(15.2 \%)$ & $332(10.2 \%)$ & 0.028 \\
\hline Clindamycin & pts & 127(3.7\%) & $5(2.5 \%)$ & 122(3.7\%) & 0.351 \\
\hline Antibiotic therapy & pts & $335(9.7 \%)$ & $169(85.4 \%)$ & 166(5.1\%) & $<0.001$ \\
\hline One infection & pts & $326(9.4 \%)$ & $161(81.3 \%)$ & 165(5.1\%) & 0.019 \\
\hline One antibiotic & pts & $220(6.4 \%)$ & $100(50.5 \%)$ & $120(3.7 \%)$ & 0.061 \\
\hline Two antibiotics & pts & $78(2.3 \%)$ & $44(22.2 \%)$ & $34(1.0 \%)$ & \\
\hline NICU start & pts & $224(6.5 \%)$ & $151(76.3 \%)$ & $73(2.2 \%)$ & $<0.001$ \\
\hline Empirical therapy & pts & $201(5.8 \%)$ & $101(51.0 \%)$ & 100(3.1\%) & 0.929 \\
\hline According to cultivation & pts & 189(5.5\%) & $106(53.5 \%)$ & $83(2.5 \%)$ & 0.019 \\
\hline Days of ATB all & day & & $8.82 \pm 6.89$ & $6.09 \pm 4.95$ & $<0.001$ \\
\hline \multicolumn{6}{|l|}{ Type of antibiotic } \\
\hline Ceftriaxone & pts & $34(1.0 \%)$ & $9(4.5 \%)$ & $25(0.8 \%)$ & 0.003 \\
\hline Ceftazidime & pts & $6(0.2 \%)$ & $3(1.5 \%)$ & $3(0.1 \%)$ & 0.982 \\
\hline Meropenem & pts & $75(2.2 \%)$ & $48(24.2 \%)$ & $27(0.8 \%)$ & 0.008 \\
\hline Penicillin & pts & $13(0.4 \%)$ & $5(2.5 \%)$ & $8(0.2 \%)$ & 0.378 \\
\hline Oxacillin & pts & $23(0.7 \%)$ & $17(8.6 \%)$ & $6(0.2 \%)$ & 0.020 \\
\hline Ciprofloxacin & day & $84(2.4 \%)$ & $57(28.8 \%)$ & $27(0.8 \%)$ & $<0.001$ \\
\hline Trimethoprim & pts & $17(0.5 \%)$ & $10(5.1 \%)$ & $7(0.2 \%)$ & 0.478 \\
\hline Gentamicin & pts & $25(0.7 \%)$ & $15(7.6 \%)$ & $10(0.3 \%)$ & 0.321 \\
\hline Others & pts & $71(2.0 \%)$ & $29(14.6 \%)$ & $42(1.3 \%)$ & 0.068 \\
\hline
\end{tabular}

NICU neurointensive care unit, ATB antibiotic

that antibiotic prophylaxis is mainly used in association with operations and only $9.7 \%$ of the total population received antibiotic therapy. Unindicated use of antibiotics contributes to the emergence and spread of multidrug- resistant bacteria, which are becoming a growing problem in healthcare facilities. Antibiotics should only be given during operations and their administration should not be prolonged in the NICU. During the prophylactic use of 
Table 9 Nosocomial infections on admission and onset in the NICU

\begin{tabular}{|c|c|c|c|c|c|}
\hline Parameter & Unit & $\mathrm{Nl}$ total & $\mathrm{NI}$ on admission & $\mathrm{NI}$ onset in NICU & $p$ value \\
\hline Number total & pts & $198(100 \%)$ & $45(22.7 \%)$ & $153(77.3 \%)$ & \\
\hline Age & pts & $57.2 \pm 15.6$ & $53.7 \pm 16.9$ & $58.3 \pm 15.1$ & 0.086 \\
\hline Male & pts & $117(59.1 \%)$ & 18(40.0\%) & $63(41.2 \%)$ & $<0.001$ \\
\hline NICU stay & day & $15.3 \pm 11.7$ & $6.9 \pm 7.2$ & $17.7 \pm 11.6$ & $<0.001$ \\
\hline \multicolumn{6}{|l|}{ Diagnoses } \\
\hline Stroke & pts & $110(55.6 \%)$ & $13(28.9 \%)$ & $97(63.4 \%)$ & \\
\hline Trauma & pts & $27(13.6 \%)$ & $3(6.7 \%)$ & $24(15.7 \%)$ & \\
\hline Tumour & pts & $33(16.7 \%)$ & $13(28.9 \%)$ & $20(13.1 \%)$ & \\
\hline Epilepsy & pts & $3(1.5 \%)$ & $0(0.0 \%)$ & $3(2.0 \%)$ & $<0.001$ \\
\hline Hydrocephalus & pts & $13(6.6 \%)$ & $7(15.6 \%)$ & $6(3.9 \%)$ & \\
\hline Infection & pts & $11(5.6 \%)$ & $9(20.0 \%)$ & $2(1.3 \%)$ & \\
\hline Others & pts & $1(0.5 \%)$ & $0(0.0 \%)$ & $1(0.7 \%)$ & \\
\hline TISS on admission & & $54.7 \pm 1.9$ & $56.0 \pm 179$ & $54.3 \pm 1.8$ & $<0.001$ \\
\hline TISS total & & $270632.8 \pm 231533.1$ & $111173.7 \pm 231533.1$ & $309492.6 \pm 234698.9$ & $<0.001$ \\
\hline GCS on admission & & $11.5 \pm 3.5$ & $12.0 \pm 3.3$ & $11.3 \pm 3.5$ & 0.234 \\
\hline APACHE II on admission & & $15.1 \pm 5.5$ & $13.6 \pm 5.4$ & $15.4 \pm 5.5$ & 0.099 \\
\hline GOS on NICU discharge & & $3.1 \pm 1.1$ & $3.5 \pm 1.2$ & $3.0 \pm 1.1$ & 0.015 \\
\hline Mortality in NICU & pts & $21(10.6 \%)$ & $3(6.7 \%)$ & 18(11.8\%) & 0.329 \\
\hline Operation & pts & $151(76.3 \%)$ & $37(82.2 \%)$ & $114(74.5 \%)$ & 0.285 \\
\hline Airways & pts & $112(56.6 \%)$ & $16(35.6 \%)$ & $96(62.7 \%)$ & 0.001 \\
\hline Mechanical ventilation & pts & $87(43.9 \%)$ & $7(15.6 \%)$ & $80(52.3 \%)$ & $<0.001$ \\
\hline Artery catheter & pts & $90(45.5 \%)$ & $6(13.3 \%)$ & $84(54.9 \%)$ & $<0.001$ \\
\hline Central venous catheter & pts & $64(32.3 \%)$ & $11(24.4 \%)$ & $53(34.6 \%)$ & 0.199 \\
\hline Lumbar drainage & pts & $36(18.2 \%)$ & $5(11.1 \%)$ & $31(20.3 \%)$ & 0.162 \\
\hline Ventricular drainage & pts & $21(10.6 \%)$ & $3(6.7 \%)$ & 18(11.8\%) & 0.329 \\
\hline Corticoids & pts & $47(23.7 \%)$ & $11(24.4 \%)$ & $36(23.5 \%)$ & 0.899 \\
\hline Transfusions & pts & $41(20.7 \%)$ & $5(11.1 \%)$ & $36(23.5 \%)$ & 0.071 \\
\hline Ulcer prophylaxis & pts & $134(67.7 \%)$ & $27(60.0 \%)$ & 107(69.9\%) & 0.210 \\
\hline Diabetes Mellitus & pts & $22(11.1 \%)$ & $3(6.7 \%)$ & 19(12.4\%) & 0.280 \\
\hline Antibiotic prophylaxis & pts & $127(64.1 \%)$ & $23(51.1 \%)$ & 104(68.0\%) & 0.038 \\
\hline Antibiotic therapy & pts & 169(85.4\%) & $28(62.2 \%)$ & $141(92.2 \%)$ & $<0.001$ \\
\hline ESBL & pts & $6(3.0 \%)$ & $1(2.2 \%)$ & $5(3.3 \%)$ & 0.719 \\
\hline MRSA & pts & $7(3.5 \%)$ & $1(2.2 \%)$ & $6(3.9 \%)$ & 0.587 \\
\hline One infection & pts & 189(95.5\%) & $45(100.0 \%)$ & 144(94.1\%) & \\
\hline Two infections & pts & $8(4.0 \%)$ & $0(0.0 \%)$ & $8(5.2 \%)$ & 0.250 \\
\hline Three infections & pts & $1(0.5 \%)$ & $0(0.0 \%)$ & $1(0.7 \%)$ & \\
\hline Bloodstream & pts & $23(11.6 \%)$ & $1(2.2 \%)$ & $22(14.4 \%)$ & 0.025 \\
\hline Vascular catheter & pts & $14(7.1 \%)$ & $1(2.2 \%)$ & $13(8.5 \%)$ & 0.149 \\
\hline Respiratory & pts & $63(31.8 \%)$ & $3(6.7 \%)$ & $60(39.2 \%)$ & $<0.001$ \\
\hline VAP & pts & $34(17.2 \%)$ & $1(2.2 \%)$ & $33(21.6 \%)$ & 0.002 \\
\hline Urinary & pts & $35(17.7 \%)$ & $5(11.1 \%)$ & $30(19.6 \%)$ & 0.189 \\
\hline Urinary catheter & pts & $33(16.7 \%)$ & $5(11.1 \%)$ & $25(16.3 \%)$ & 0.255 \\
\hline Wound without operation & pts & $2(1.0 \%)$ & $1(2.2 \%)$ & $1(0.7 \%)$ & 0.355 \\
\hline Wound with operation & pts & $70(35.4 \%)$ & $35(77.8 \%)$ & $35(22.9 \%)$ & $<0.001$ \\
\hline
\end{tabular}


Table 9 Nosocomial infections on admission and onset in the NICU (Continued)

\begin{tabular}{|c|c|c|c|c|c|}
\hline Parameter & Unit & $\mathrm{NI}$ total & $\mathrm{NI}$ on admission & $\mathrm{NI}$ onset in NICU & $p$ value \\
\hline \multicolumn{6}{|c|}{ Wound complication } \\
\hline Liquorrhoea & pts & $14(7.1 \%)$ & $7(15.6 \%)$ & $7(4.6 \%)$ & 0.012 \\
\hline Dehiscence & pts & $11(5.6 \%)$ & $9(20.0 \%)$ & $2(1.3 \%)$ & $<0.001$ \\
\hline Fistula & pts & $6(3.6 \%)$ & $3(6.7 \%)$ & $3(2.0 \%)$ & 0.105 \\
\hline
\end{tabular}

NICU neurointensive care unit, TISS Therapeutic Intervention Scoring System, GCS Glasgow Coma Scale, APACHE Acute Physiology and Chronic Health Evaluation, GOS Glasgow Outcome Scale, ESBL Extended spectrum beta-lactamase, MRSA Methicillin-resistant Staphylococcus aureus, VAP ventilator associated pneumonia

antibiotics it is essential not only to keep to the indication, but also to maintain the time of administration. However, this study confirmed that antibiotic prophylaxis policy is an important task, because antibiotic prophylaxis was found to be a predictor of nosocomial infection in the neurocritical care population. While using antibiotics, it is essential to maintain the correct administration and not use antibiotics during the colonisation of the patient, but only for the infection. Timing, dosage and tissue penetration are important in their administration.

Our microbiological screening was the same for all patients, who can therefore be compared easily. The unified system included nose, throat, trachea, skin, urine and rectum tests from admission, so that we would know what the patient was admitted with, and then regularly every three days. This means that this microbiological screening sometimes fell on the weekend, which at first was difficult to implement in the microbiological department. Regular microbiological screening from admission took place every three days, giving us an overview of the microbiological state of the patient and allowing us to find colonization of multidrug-resistant bacteria [18] and further perform the targeted antibiotic treatment of nosocomial infections.

Although it would be better to have single-patient boxes, the lay-out of four divided rooms provides some of the benefits and enables the isolation of patients with multidrug-resistant bacteria ESBL and MRSA, as it is very important to isolate these patients so that these bacteria do not spread to the rest of the NICU and the other patients. Our results show that over a ten-year period we did not have a large incidence of the multidrug-resistant bacteria
ESBL and MRSA, while there was not a single case of VRE. This is in contrast to the Minhas [19] study, where he mentioned $2.5 \%$ of VRE in the neurosurgical and neurological intensive care unit.

This study confirmed that accesses are still a risk factor for nosocomial infection. Due to increasing numbers of invasive medical procedures in neurocritical care, local preventive infection control management has an important task. Although preventive multimodal strategy is widely known to reduce nosocomial infection and multidrug resistant bacteria, it is sometimes difficult to maintain. Nonetheless, the results of this study show the importance of this maintenance. We present our 10 year prospective infection control management, which was efficient, as it led to a rate of $4.4 \%$ nosocomial infections in acute neurological and neurosurgical care patients. Due to multiple testing, there is a higher probability of family-wise error. On the other hand, the results must be read in context, not every p-value below 0.05 is commented on as a finding.

This study showed prospective infection control management in 3464 neurocritically care patients. Although they all came from a single neurocentre, which is a limitation of this study, there are already many more epidemiologic studies regarding nosocomial infection control and multi-drug resistant bacteria from the medical and surgery intensive care units than from neurocritical care units, whether neurosurgical or neurological, and very few studies concerned with neurological-neurosurgical critical care units $[19,20]$. In this area, more studies focus on specific diagnoses $[1,2,7,21,22]$ than whole neurocritical care populations.

Table 10 Multivariate logistic regression analysis of nosocomial infection onset in NICU

\begin{tabular}{lllll}
\hline Multivariate analysis & & & \\
Nosocomial infections predictors & Odds Ratio & Lower CL 95\% & Upper CL 95\% & 1.16 \\
\hline NICU stay (per day) & 1.14 & 1.12 & 3.99 \\
Airways & 2.69 & 1.81 & 7.70 & $<0.001$ \\
Urine catheter & 2.77 & 1.00 & 2.97 & 0.001 \\
Transfusions & 1.79 & 1.07 & 3.97 & 0.025 \\
Wound complications & 2.30 & 1.33 & 0.74 & 0.003 \\
Antibiotic prophylaxis & 0.50 & 0.34 & & $<.001$ \\
\hline
\end{tabular}




\section{Conclusions}

This study showed that this preventive multimodal nosocomial infection control management was efficient, because it gave low rates of nosocomial infections (4.2\%), both ESBL and MRSA in a mere $0.9 \%$ of patients each and not a single case of VRE. Strong predictors for the onset of nosocomial infections were accesses such as airways and urine catheters, NICU stay, antibiotic prophylaxis, wound complications and transfusion. This study confirmed the well-known fact that nosocomial infections are associated with worse outcome, higher cost and longer NICU stay.

\begin{abstract}
Abbreviations
APACHE: Acute Physiology and Chronic Health Evaluation; ASA: American Society of Anesthesiologists; ATB: antibiotic; BMI: body mass index; CRP: Creactive protein; ESBL: Extended spectrum beta-lactamase; ETT: endotracheal tube; GCS: Glasgow Coma Scale; GOS: Glasgow Outcome Scale; ICH: intracerebral haemorrhage; MRSA: Methicillin-resistant Staphylococcus aureus; Nl: nosocomial infection; NICU: neurointensive care unit; SAH: subarachnoid haemorrhage; STSP: Staphylococcus species; TISS: Therapeutic Intervention Scoring System; TST: tracheostomy tube; VRE: Vancomycin-resistant enterococcus
\end{abstract}

\section{Acknowledgement}

We thank the translator and native English speaker Henry Morgan (BA honours) for the correction of the English text. This study was published as an abstract of the $23^{\text {rd }}$ annual congress of the European Society of Intensive Care Med Experimental 2016;4(S1):426.

\section{Funding}

This study was supported by grants from the Scientific Board of the hospital, number VR 140312.

\section{Availability of data and materials}

The datasets obtained during this study are available from the corresponding author on reasonable request.

\section{Authors' contributions}

VS, OB, DF, ZB, PS: revising it critically for important intellectual content, final approval of the manuscript, read and agreed to be accountable for all aspects of the work in ensuring that questions related to the accuracy or integrity of any part of the work are appropriately investigated and resolved. VS: conception and design, acquisition of data, interpretation of data; drafting the manuscript, OB: statistical analysis, interpretation of data, DF, ZB: acquisition of data, interpretation of data. PS: conception.

\section{Ethics approval and consent to participate}

The study was approved by the Liberec hospital Ethics Committees for Multicentric Clinical Trials (č.j. EK27/2008). All participants gave written informed consent prior to all measurements and agreed upon publication.

\section{Consent for publication}

Not applicable.

\section{Competing interests}

The authors declare that they have no competing interests.

\section{Publisher's Note}

Springer Nature remains neutral with regard to jurisdictional claims in published maps and institutional affiliations.

\section{Author details}

${ }^{1}$ Neurocenter, Neurointensive Care Unit, Regional Hospital, Husova 357/10, Regional Hospital, 46063 Liberec, Czech Republic. ${ }^{2}$ Department of Neurosurgery, Military University Hospital and First Medical School, Charles University, Prague, Czech Republic. ${ }^{3}$ Department of Clinical microbiology and immunology, Antibiotic Centre, Regional Hospital, Liberec, Czech Republic.
${ }^{4}$ Neurocenter, Department of Neurosurgery, Regional Hospital, Liberec, Czech Republic.

Received: 6 November 2017 Accepted: 28 February 2018

Published online: 07 March 2018

\section{References}

1. Zygun DA, Zuege DJ, Boiteau PJ, Laupland KB, Henderson EA, Kortbeek JB, Doig CJ. Ventilator-associated pneumonia in severe traumatic brain injury. Neurocrit Care. 2006;5:108-14.

2. Murthy SB, Moradiya Y, Shah J, Merkler AE, Mangat HS, ladacola C, et al. Nosocomial Infections and Outcomes after Intracerebral Hemorrhage: A Population-Based Study. Neurocrit Care. 2016;25:178-84.

3. Foreman PM, Chua M, Harrigan MR, Fisher WS 3rd, Vyas NA, Lipsky RH, Walters BC, Tubbs RS, Shoja MM, Griessenauer CJ. Association of nosocomial infections with delayed cerebral ischemia in aneurysmal subarachnoid hemorrhage. J Neurosurg. 2016;125:1383-9.

4. Westendorp WF, Nederkoorn PJ, Vermeij JD, Dijkgraaf MG, van de Beek D. Post-stroke infection: a systematic review and meta-analysis. BMC Neurol. 2011;11:110

5. Bronchard R, Albaladejo P, Brezac G, Geffroy A, Seince PF, Morris W, et al. Early onset pneumonia: risk factors and consequences in head trauma patients. Anesthesiology. 2004;100:234-9.

6. Bassetti M, De Waele JJ, Eggimann P, Garnacho-Montero J, Kahlmeter G, Menichetti F, et al. Preventive and therapeutic strategies in critically ill patients with highly resistant bacteria. Intensive Care Med. 2015;41:776-95.

7. Ohwaki K, Yano E, Nagashima H, Nakagomi T, Tamura A. Impact of infection on length of intensive care unit stay after intracerebral hemorrhage. Neurocrit Care. 2008;8:271-5.

8. Josephson SA, Moheet AM, Gropper MA, Nichols AD, Smith WS. Ventilatorassociated pneumonia in a neurologic intensive care unit does not lead to increased mortality. Neurocrit Care. 2010;12:155-8.

9. Chen YY, Chou YC, Chou P. Impact of nosocomial infection on cost of illness and length of stay in intensive care units. Infect Control Hosp Epidemiol. 2005;26:281-7.

10. Higgins TL, McGee WT, Steingrub JS, Rapoport J, Lemeshow S, Teres D. Early indicators of prolonged intensive care unit stay: impact of illness severity, physician staffing, and pre-intensive care unit length of stay. Crit Care Med. 2003:31:45-51.

11. Halperin JJ, Moran S, Prasek D, Richards A, Ruggiero C, Maund C. Reducing Hospital-Acquired Infections Among the Neurologically Critically III. Neurocrit Care. 2016;25:170-7.

12. Traa MX, Barboza L, Doron S, Snydman DR, Noubary F, Nasraway SA Jr. Horizontal infection control strategy decreases methicillin-resistant Staphylococcus aureus infection and eliminates bacteremia in a surgical ICU without active surveillance. Crit Care Med. 2014:42:2151-7.

13. Morgan DJ, Rogawski E, Thom KA, Johnson JK, Perencevich EN, Shardell M, et al. Transfer of multidrug-resistant bacteria to healthcare workers' gloves and gowns after patient contact increases with environmental contamination. Crit Care Med. 2012:40:1045-51.

14. Kollef MH, Micek ST. Antimicrobial stewardship programs: mandatory for all ICUs. Crit Care. 2012;16:179.

15. Rimawi RH. Just Say "Stop": Avoiding Prolonged Empiric Antibiotics. Crit Care Med. 2015:43:2675-6.

16. Ziakas PD, Anagnostou T, Mylonakis E. The prevalence and significance of methicillin-resistant Staphylococcus aureus colonization at admission in the general ICU Setting: a meta-analysis of published studies. Crit Care Med. 2014:42:433-44.

17. Ziakas PD, Zacharioudakis IM, Zervou FN, Mylonakis E. Methicillin-resistant Staphylococcus aureus prevention strategies in the ICU: a clinical decision analysis*. Crit Care Med. 2015;43:382-93.

18. Sarikonda KV, Micek ST, Doherty JA, Reichley RM, Warren D, Kollef MH. Methicillin-resistant Staphylococcus aureus nasal colonization is a poor predictor of intensive care unit-acquired methicillin-resistant Staphylococcus aureus infections requiring antibiotic treatment. Crit Care Med. 2010;38: 1991-5.

19. Minhas P, Perl TM, Carroll KC, Shepard JW, Shangraw KA, Fellerman D, et al. Risk factors for positive admission surveillance cultures for methicillinresistant Staphylococcus aureus and vancomycin-resistant enterococci in a neurocritical care unit. Crit Care Med. 2011;39:2322-9. 
20. Dettenkofer M, Ebner W, Els T, Babikir R, Lucking C, Pelz K, et al. Surveillance of nosocomial infections in a neurology intensive care unit. J Neurol. 2001;248:959-64.

21. Divani AA, Hevesi M, Pulivarthi S, Luo X, Souslian F, Suarez Jl, et al. Predictors of nosocomial pneumonia in intracerebral hemorrhage patients: a multi-center observational study. Neurocrit Care. 2015;22:234-42.

22. Hilker R, Poetter C, Findeisen N, Sobesky J, Jacobs A, Neveling M, et al. Nosocomial pneumonia after acute stroke: implications for neurological intensive care medicine. Stroke. 2003;34:975-81.

Submit your next manuscript to BioMed Central and we will help you at every step:

- We accept pre-submission inquiries

- Our selector tool helps you to find the most relevant journal

- We provide round the clock customer support

- Convenient online submission

- Thorough peer review

- Inclusion in PubMed and all major indexing services

- Maximum visibility for your research

Submit your manuscript at www.biomedcentral.com/submit
Biomed Central 